\title{
Effect of figure-ground contrast and contour orientation on the temporal range of apparent movement'
}

\author{
ROBERT H. POLLACK \\ INSTITUTE FOR JUVENILE RESEARCH, CHICAGO
}

The range of interstimulus intervals permitting the detection of apparent movement was investigated as a function of figure-ground contrast of the stimuli and also as a function of the contour orientations of the stimulus figures. It was found that the greatest interval ranges occurred when figureground contrast was maximal and when the contours of the figures were parallel to each other. The younger of the two Ss showed wider ranges throughout.

Apparent movement, like backward figural masking, represents a temporal conflict between the conditions of physical stimulation and the phenomenon reported. As is the case with figural masking (Pollack, 1965), physically, two stimuli are presented successively with varying intervals between them. In the case of masking, when detection of the figure to be masked occurs, the subjective phenomenon is of simultaneous exposure of the figures. In the case of apparent movement, a single figure is reported as moving continuously across the visual field.

The earlier investigation of figural masking made it clear that both figure-ground contrast and contour orientation played decisive roles in influencing the range of interstimulus intervals which permitted masking. The greater the contrast of the mask with its ground relative to the target, the wider the range of interstimulus intervals permitting masking. Also, parallel contours of target and mask and the absence of angles within the target widened the interstimulus interval. It is proposed that the same rules apply to apparent movement.

As with figural masking, it is suggested that apparent movement represents the apparent displacement of contours toward each other. Therefore any conditions which would promote contour attraction would be expected to widen the range of interstimulus intervals eliciting reports of movement. Evidence for the effectiveness of figure-ground contrast has been shown not only for figural masking, but also for the concentric circle illusion (Oyama, 1961). Evidence for the effect of contour orientation on contour displacement has been gathered by George (1962), Pollack (1964), and Pollack \& Chaplin (1964).

It was expected, therefore, that the range of interstimulus intervals permitting the report of apparent movement would become greater as figure-ground contrast of the stimuli was increased, and that having the contours of the stimulus figures parallel rather than potentially intersecting would also increase the range.
The range of interstimulus intervals was chosen as the dependent variable for two reasons. First, it seemed to offer a sensitive single index for the tolerance limits between which successive stimulation in geographically separate locations would be perceived as a continuous change of position. Second, it offered a dimension which would be comparable to that of figural masking, which it appears to resemble (Werner, 1935). Orlansky (1940) found another form of this measure (cycles per second) to be effective in establishing that figural similarity widens the range of interstimulus intervals in which movement is percelved. The measure is derived from substraction of the transition threshold between simultaneity and movement from that between movement and succession.

Subjects 2

Two adult $S s$, a male in his thirties $\left(S_{1}\right)$ and a female in her twenties $\left(S_{2}\right)$ served as trained $S s$ in all conditions of the experiment.

\section{Apparatus}

The apparent movement sequence was produced by using a three-channel electronic tachistoscope (Scientific Prototype Corporation, Model GA). Illumination as measured at the eyepiece by a Macbeth Lluminometer was $5.0 \mathrm{ft}$. c. for all channels.

\section{Procedure}

Six pairs of stimuli were used, providing two contour orientations and three figure-ground contrast values for each orientation. For the parallel contour condition, three pairs of $12.7 \mathrm{~mm}$ squares, white, light gray or mid-gray on a black ground, were used. For the non-parallel condition, squares of the same size were used, one pair for each of the three contrast conditions, but they were rotated $45^{\circ}$, appearing as diamonds. The firs̀t-presented member of each stimulus pair was mounted so that its innermost point was $6.35 \mathrm{~mm}$ to the left of the center of the field, and the secondpresented stimulus was $6.35 \mathrm{~mm}$ to the right, so that the interstimulus distance subtended, in all cases, a visual angle of $39^{\prime} 40^{\prime \prime}$. The vertical extent of each stimulus was $56^{\prime} 22^{\prime \prime}$, the maximum horizontal extent of a stimulus pair $2^{\circ} 32 ' 24 "$. Viewing was binocular. A blank black field was presented during the variable interstimulus interval.

The stimuli were always presented for $50 \mathrm{msec}$. The interstimulus interval was variable in $10 \mathrm{msec}$. steps from 10 to $150 \mathrm{msec}$.

Upper and lower apparent movement thresholds were obtained from both subjects for each of the six stimulus 


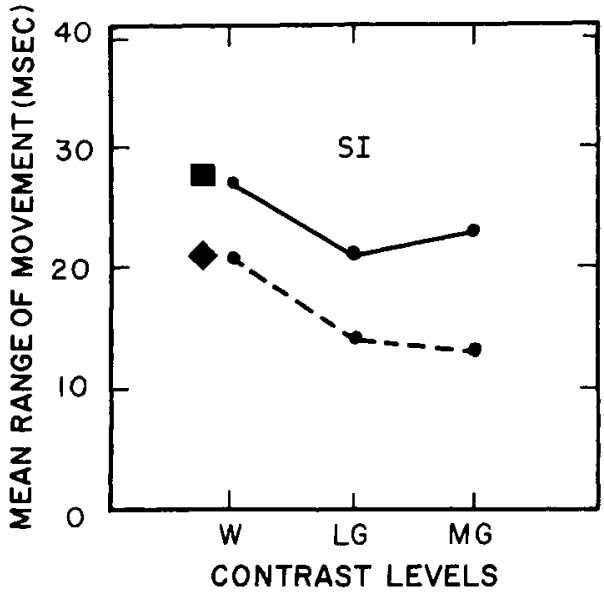

Fig. 1. Range of interstimulus intervals permitting detection of apparent movement as a function of figure-ground contrast of initial stimulus for $S_{1}$ (male).

pairs, using the method of limits. Each apparent movement range was based on 32 measures, from two runs, separated by at least a week, of eight ascending and eight descending series, run in counterbalanced order.

In each sequence, Ss were shown instances in which the stimuli were clearly successive, moving, or clearly simultaneous. They were told to say "two" when the figures were successive or simultaneous or "one" when a single figure was seen to move from left to right. Each trial consisted of a series of single sequences of stimulus events.

\section{Results and Discussion}

A ( 3 contrasts) by ( 2 contour orientations) analysis of variance was performed for each $\mathrm{S}$. Both variables were associated with significant differences in apparent movement interstimulus intervals for both Ss (Orientation $-S_{1}, F=35.84, \mathrm{df}=1 / 186, \mathrm{p}<.01$, and $\mathrm{S}_{2}, \mathrm{~F}=15.89$, $\mathrm{df}=1 / 186, \mathrm{p}<.01 ;$ Contrast $-\mathrm{S}_{1}, \mathrm{~F}=11.05, \mathrm{df}=2 / 186$, $\mathrm{p}<.01$ and $\left.\mathrm{S}_{2}, \mathrm{~F}=3.26, \mathrm{df}=2 / 186, \mathrm{p}<.05\right)$. The interaction was not significant for either S. (See Figs. 1 and 2). As was expected, the greater the figure-ground contrast of the stimuli, the wider was the range of interstimulus intervals over which movement was reported. At the same time, it is clear that the range was wider when the neighboring contours of the two stimulus figures were parallel than when they were not.

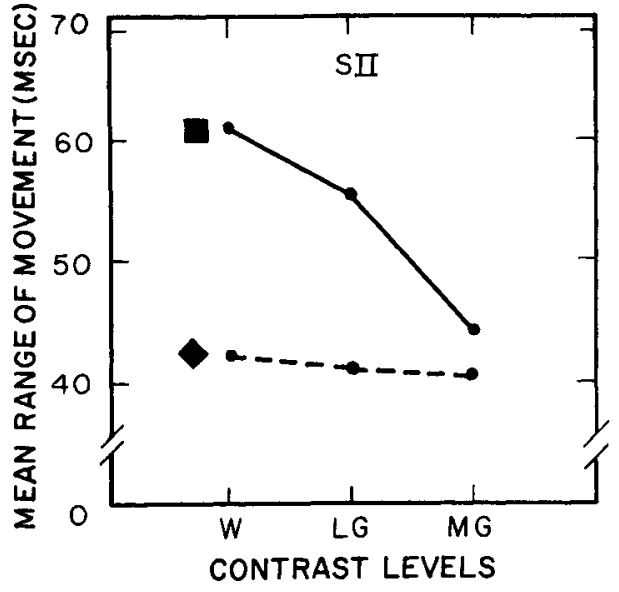

Fig. 2. Range of interstimulus intervals permitting detection of apparent movement as a function of figure-ground contrast of initial stimulus for $S_{2}$ (female).

Separate one-way analyses of variance for each orientation for each subject revealed that although the contrast effect was similar in all cases, it was not significant for the diamond orientation in $\mathrm{S}_{2}$. It is possible that the effect of orientation is more potent than that of contrast.

\section{References}

George, F. H. Acuity and the statistical theory of figural aftereffects. J. exp. Psychol. 1962, 63, 423-425.

Orlansky, $\mathbf{J}$. The effect of similarity and difference in form on apparent visual movement. Arch. Psychol., N. Y., 1940, 246, $1-88$.

Oyama, $\mathbf{T}$. The illusion of concentric circles as a function of hue and brightness. Hokkaido Rep. Psychol., 1961, 6, No. 3.

Pollack, R. H. The effects of fixation upon the apparent magnitude of bounded horizontal extent. Amer. J. Psychol., 1964, 77, 187-192.

Pollack, R. H. Effects of figure-ground contrast and contour orientation on figural masking. Psychon. Sci., 1965, 2, 369-370.

Pollack, R. H., \& Chaplin, M. R. The effects of prolonged stimulation by components of the Mueller-Lyer figure upon the magnitude of illusion. Percept. mot. Skills, 1964, 18, 377-382.

Werner, H. Studies on contour: I. Qualitative analysis. Amer. J. Psychol., 1935, 47, 40-64.

\section{Notes}

1. This research was supported by Grant No. HD 01433 awarded by the National Institute of Child HeaIth and Human Development. 2. Acknowledgement is given to Mr. Gene Skoff and Mrs. Jocelyn Marsh who served as subjects and experimenters. 